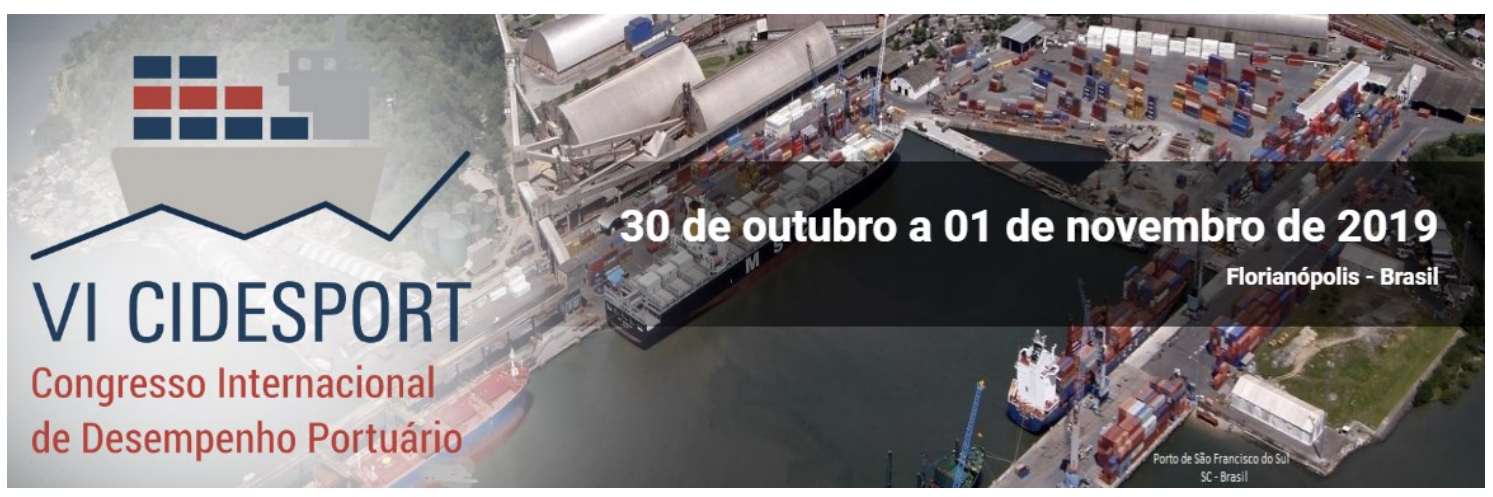

\title{
ANÁLISE DOS FATORES INTERNOS E EXTERNOS QUE AFETAM A COMPETITIVIDADE DOS PORTOS PÚBLICOS BRASILEIROS
}

\author{
Rafael Fontoura Andriotti \\ Universidade Federal do Rio Grande do Sul \\ Francisco José Kliemann Neto \\ Universidade Federal do Rio Grande do Sul
}

\begin{abstract}
Resumo: Este artigo apresenta uma pesquisa qualitativa com especialistas do setor portuário brasileiro. Essa pesquisa permitiu identificar os fatores afetam que a competitividade dos portos e as ferramentas de gestão utilizadas. Além disso, foram identificadas as ferramentas que deveriam ser utilizadas para o efetivo gerenciamento dos fatores elencados, e os resultados foram confrontados com os caminhos apontados pela literatura. Como principais desdobramentos, destacam-se duas abordagens: setorial e gerencial. $\mathrm{Na}$ análise setorial, três aspectos devem ser tratados de forma sequencial: conjunto legal, planejamento e alinhamento entre órgãos. Já na análise gerencial, a ferramenta de sistema gerencial de custeio, a qual irá integrar as demais ferramentas e bases de dados para gerar informações gerenciais, deve ser implementada.
\end{abstract}

Palavras-chave: Governança. Gestão portuária. Eficiência dos portos brasileiros. Portos públicos brasileiros.

\section{INTRODUÇÃO}

Apesar da crise econômica que afeta o Brasil, a movimentação de cargas do setor portuário brasileiro, mais precisamente os Portos, aumentou 8,3\% de 2016 para 2017 e 3\% de 2017 para 2018 (ANTAQ, 2019). Por se tratarem de empreendimentos de capital intensivo (Tae-Woo Lee e Flynn, 2011; Tovar e Wall, 2019), onde são necessárias grandes somas de capital para sua instalação e manutenção, agravado pelo fato de grande parte dos custos serem fixos, muito se tem discutido sobre eficiência portuária.

Segundo Ferretti et al. (2017), se um porto tem receitas maiores que seus custos, ele é considerado eficiente. Já para Costa, Meza e Roboredo (2018) e Julien, Cowie e Monios (2018), a demanda é um fator de grande impacto para a eficiência portuária. Segundo Schøyen et al. (2018), a intensidade competitiva afeta a eficiência de um porto. Por consequência, um porto de maior porte tende a ser mais eficiente (Tovar e Wall, 2019). De forma geral, a literatura define eficiência portuária como a razão dos outputs pelos inputs (Lam e Notteboom, 2014; Chen e Lam, 2018; Julien, Cowie e Monios, 2018; Ferretti et al., 2017; Beuren et al., 2018; Gobbi et al., 2019). Schøyen et al. (2018) definem três fatores que influenciam a eficiência de um porto: pontualidade, preço e confiabilidade. Para Julien, Cowie e Monios (2018), a eficiência técnica também é medida pela razão dos outputs sobre os inputs, no entanto esta eficiência retrata o estado das coisas no curto prazo. Adicionalmente, definem que a

\footnotetext{
* A revisão gramatical, ortográfica, ABNT ou APA foi realizada pelos autores.
} 
VI CIDESPORT/2019

Congresso Internacional

de Desempenho Portuário

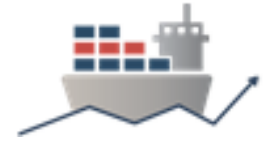

produtividade avalia a evolução da eficiência ao longo do tempo e que existem dois tipos de ganhos: mudança de eficiência e mudança tecnológica.

Tendo em vista a importância dos portos para a economia de uma país e do alto investimento relacionado ao segmento, a literatura apresenta diversos estudos sobre eficiência portuária. Estes estudos referem-se a terminais de contêineres (Peng et al., 2019), ou ao porto de forma geral (Beuren et al., 2018; Chen e Lam, 2018; Guner, 2018; Gobbi et al., 2019; Park et al., 2019). A Análise de Envoltória de Dados (Data Envelopment Analysis - DEA) é a técnica mais comumente utilizada na literatura para determinar a eficiência relativa de um conjunto de Portos (Beuren et al., 2018; Chen e Lam, 2018; Guner, 2018; Gobbi et al., 2019; Park et al., 2019). Xiao (2012), Qu, Wang e Zeng (2017) e Tovar e Wall (2019) analisaram quais fatores deveriam ser considerados nessa análise. Guner (2018) incorporou a opinião de especialistas na análise do DEA. Beuren et al. (2018) também analisaram quais são os inputs e outputs utilizados nos estudos de DEA no setor portuário, e estes parecem convergir para capacidade de movimentação, comprimento do cais e calado máximo como inputs, e quantidade movimentada e quantidade de atracações como outputs.

\section{REFERENCIAL TEÓRICO}

Em comum aos estudos de DEA supracitados, destaca-se a falta de uma definição homogênea para o termo 'eficiência portuária'. Bandara, Nguyen e Chen (2013), Vieira, Kliemann Neto e Amaral (2014), Chen e Lam (2018) e Gobbi et al. (2019) também apresentam definições distintas para o termo. Talvez um reflexo, ou até mesmo uma causa, dessa falta de homogeneidade para o termo pode ser atribuída às recentes mudanças no tipo de gestão dos portos (Public Service Ports, Tool Ports, Landlord Ports e Private Service Ports). Bandara, Nguyen e Chen (2013), Zhang (2016), Ferretti et al. (2017) e Beuren et al. (2018) apresentam uma revisão acerca dos tipos de gestão portuária e as principais características de cada tipo.

Mudanças regulatórias no setor, não só no Brasil (Beuren et al., 2018), mas em todo o mundo (Brooks, 2017; Brooks, Cullinane e Pallis, 2017), têm suscitado muita discussão acerca da governança portuária. Para Brooks, Cullinane e Pallis (2017), o Sistema de Governança Portuária atual é produto destas mudanças ao longo do tempo. De acordo com Brooks, Cullinane e Pallis (2017), as mudanças legais no setor Portuário Brasileiro, em termos gerais, convergem com o que acontece em outros países, observando-se a inclinação para portos landlord com menor participação estatal (participação e velocidade de concessão/privatização variando dependendo do país). De acordo com Ferretti et al. (2017), a consequência destas mudanças é que as Autoridades Portuárias (AP) ao redor do mundo estão modificando sua natureza e papel, tornando-se mais ativas no que tange à governança do sistema logístico e adotando um comportamento gerencial e empreendedor.

Nesse contexto, é latente a necessidade de mecanismos de governança para o setor portuário (Vieira, Kliemann Neto e Amaral, 2014; Wilmsmeier e Monios, 2016; Brooks, Cullinane e Pallis, 2017; Chen, Pateman e Sakalayen, 2017; Zhang et al., 2019). Wilmsmeier e Monios (2016) definem governança como 'instituições, mecanismos e processos através dos quais autoridade econômica, política e administrativa são exercidas'. Zhang et al. (2019) mostram que a quantidade de estudos sobre governança portuária tem aumentado na literatura, apesar de ainda ser relativamente baixo. De acordo com Vieira, Kliemann Neto e Amaral (2014), existem gaps na literatura que tornam difícil responder algumas questões básicas associadas à governança portuária: (i) quem faz a governança, (ii) o que é alvo da governança, 
(iii) como é realizada a governança e (iv) qual o seu objetivo. Brooks, Cullinane e Pallis (2017) acrescentam ainda que existem poucas evidências de melhores práticas sobre governança portuária. Os autores dizem ainda que o meio termo entre a privatização total e o controle centralizado é confuso, e que não há modelos claros e transparentes de governança.

Tendo em vista as lacunas identificadas por Vieira, Kliemann Neto e Amaral (2014), Zhang et al. (2018) fizeram uma revisão sistemática sobre os dois primeiros gaps. De uma forma geral, encontraram evidências (i) de que organizações governamentais e organizações portuárias são as principais envolvidas nestas questões, (ii) do aumento do envolvimento estatal nos EUA, Brasil e China e (iii) que as APs têm, geralmente, maior autonomia na gestão das operações. Como objeto das ações de governança, citam-se atividades portuárias específicas e os arranjos institucionais.

$\mathrm{Na}$ sequência, Zhang et al. (2019) realizaram um estudo para responder as questões (i) como é realizada a governança e (ii) para qual objetivo. No que tange ao objetivo, estes podem ser classificados em: eficiência e eficácia. A eficiência, que pode ser mensurada e necessita de um benchmark, é traduzida como a capacidade do porto maximizar seus outputs dado seus inputs. A eficiência, segundo os autores, pode ser de quatro tipos principais: (i) técnica, (ii) alocativa, (iii) econômica e (iv) de custos.

Segundo esses autores, as principais características da eficácia estão relacionadas à qualidade dos serviços prestados e atendimento de demandas regulatórias. Zhang et al. (2019) definem a eficácia como a percepção dos usuários versus a eficiência do porto.

Apesar do aumento da literatura sobre governança portuária relativamente ao século passado, validado pela quantidade de artigos relacionados, não se tem uma conclusão definitiva de quais as ferramentas utilizadas para realizá-la (Zhang et al., 2019). Estudos relacionados a ferramentas de governança aplicadas ao ambiente Portuário Brasileiro são muito escassos, e dos 118 artigos utilizados no estudo de Zhang et al. (2019) apenas 12 são relacionados a países do Continente Americano. Apesar de o espectro de artigos ser limitado a 118, Zhang et al. (2019) categorizaram as ferramentas de governança em 3 níveis: institucional, estratégico e gerencial. $\mathrm{O}$ Quadro 1 apresenta as ferramentas de nível gerencial definidas por Zhang et al. (2019), sua definição, tipos e referências.

\begin{tabular}{|c|c|c|c|}
\hline Ferramenta & Definição & Tipos & Referências \\
\hline Precificação & $\begin{array}{l}\text { Formação da } \\
\text { estrutura tarifária e } \\
\text { precificação. }\end{array}$ & $\begin{array}{l}\text { Infraestrutura, } \\
\text { infraestrutura }\end{array}$ & $\begin{array}{l}\text { Tae-Woo Lee e Flynn } \\
(2011), \quad \text { Bandara, } \\
\text { Nguyen e Chen (2013), } \\
\text { Lam e Notteboom } \\
(2014)\end{array}$ \\
\hline Concessão & $\begin{array}{ll}\text { Concessão } & \text { do } \\
\text { governo ou } & \text { da } \\
\text { autoridade } & \\
\text { portuária a } & \text { um } \\
\text { operador } & \text { por } \\
\text { determinado } & \\
\text { período. } & \\
& \end{array}$ & $\begin{array}{l}\text { Arrendamento de longo } \\
\text { prazo, Licenças de } \\
\text { operação e Build- } \\
\text { Operate-Transfer }\end{array}$ & $\begin{array}{ll}\text { Notteboom } & (2006) ; \\
\text { Farrell } & (2012) ; \\
\text { Notteboom Pallis e } \\
\text { Farrell (2012); Chen e } \\
\text { Liu (2015); Ferrari, } \\
\text { Parola e Tei (2015) }\end{array}$ \\
\hline $\begin{array}{l}\text { Gestão } \\
\text { relacionamento } \\
\text { de clientes }\end{array}$ & $\begin{array}{l}\text { Práticas e diretrizes } \\
\text { que a AP segue ao } \\
\text { interagir r com } \\
\text { usuários } \\
\end{array}$ & $\begin{array}{l}\text { Liderança de custos, } \\
\text { diferenciação }\end{array}$ & $\begin{array}{l}\text { Baltazar e } \quad \text { Brooks } \\
\text { (2006); Verhoeven } \\
\text { (2010); De Langen e } \\
\text { Van der Lugt (2017) }\end{array}$ \\
\hline
\end{tabular}


VI CIDESPORT/2019

Congresso Internacional

de Desempenho Portuário

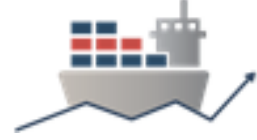

\begin{tabular}{|c|c|c|c|}
\hline $\begin{array}{l}\text { Monitoramento } \\
\text { mensuração }\end{array}$ & $\begin{array}{l}\text { Avaliação contínua } \\
\text { dos processos para } \\
\text { melhorar } \quad 0 \\
\text { desempenho }\end{array}$ & $\begin{array}{l}\text { Monitoramento de } \\
\text { preços, monitoramento } \\
\text { de emissões dos } \\
\text { navios, monitoramento } \\
\text { de concessões, } \\
\text { monitoramento da } \\
\text { qualidade }\end{array}$ & $\begin{array}{l}\text { Lam e Notteboom } \\
\text { (2014); Wilsmeier e } \\
\text { Monios (2016); Chen, } \\
\text { Pateman e Sakalayen. } \\
\text { (2017); Monios (2017) }\end{array}$ \\
\hline $\begin{array}{l}\text { Controle } \\
\text { regulatório }\end{array}$ & $\begin{array}{l}\text { Ferramenta } \\
\text { mandatória para } \\
\text { guiar as atividades } \\
\text { com transparência, } \\
\text { previsibilidade e de } \\
\text { maneira } \\
\text { responsável }\end{array}$ & $\begin{array}{l}\text { Internacional, Nacional, } \\
\text { Local }\end{array}$ & $\begin{array}{l}\text { Lam e Notteboom } \\
\text { (2014); Coto-Millán et } \\
\text { al. (2016); Brooks, } \\
\text { Cullinane e Pallis } \\
\text { (2017); Van de Voorde } \\
\text { e Verhoeven (2017) }\end{array}$ \\
\hline $\begin{array}{l}\text { Gestão } \\
\text { segurança }\end{array}$ & $\begin{array}{lr}\begin{array}{l}\text { Assegurar } \\
\text { segurança } \\
\text { operacional } \\
\text { porto }\end{array} & \text { do } \\
\end{array}$ & $\begin{array}{l}\text { Instalações, Terminais, } \\
\text { Porto }\end{array}$ & $\begin{array}{l}\text { Brooks e Cullinane } \\
\text { (2006); Eski (2016) }\end{array}$ \\
\hline $\begin{array}{l}\text { Tecnologia } \\
\text { informação } \\
\text { comunicação }\end{array}$ & $\begin{array}{lr}\text { Sistemas } & \text { de } \\
\text { informação do porto }\end{array}$ & $\begin{array}{l}\text { Port Community Sistem } \\
\text { (PCS), Sistemas de } \\
\text { Informação }\end{array}$ & $\begin{array}{lr}\text { Lambrou, } & \text { Pallis } \\
\text { Nikitakos } & \text { (2008); } \\
\text { Cepolina e Ghiara } \\
\text { (2013); Sorour e Abdul- } \\
\text { Mageed (2016) }\end{array}$ \\
\hline
\end{tabular}

Quadro 1: Ferramentas utilizadas na governança portuária.

Fonte: Adaptado de Zhang et al. (2019).

\subsection{Discussão econômica}

O framework definido por Zhang et al. (2019) é útil para organizar as ferramentas em grandes grupos. Em comum às ferramentas apresentadas, cita-se a ausência da discussão da economicidade das operações e dos serviços prestados. Entende-se que esta variável deve ser levada em consideração, já que os efeitos econômicos dos processos avaliados devem ser incorporados no processo de gestão e na tomada de decisões gerenciais.

Mesmo apresentando relativamente pouca literatura sobre o assunto, os autores parecem não convergir inteiramente sobre as questões. Exemplo disso são as diferentes abordagens de custeio propostas para o setor portuário (Luo et al., 2009, Tae-Woo Lee e Flynn, 2011; Bandara, Nguyen e Chen, 2013; Cheng e Yang, 2017; Chen e Lam, 2018). Para Bandara, Nguyen e Chen (2013), a ferramenta de custeio integra as estratégias do porto. Para Cheng e Yang (2017), a precificação e o planejamento da capacidade um porto são os principais aspectos a serem melhor desenvolvidos na busca da melhoria da eficiência portuária. Outro ponto de não convergência é sobre qual custo deve ser considerado para a formação de tarifas: apenas o custo operacional (Modelo Europeu subsidiado pelo Estado), ou o custo total (Modelo Britânico sem subsídio) (Tae-Woo Lee e Flynn, 2011). Tae-Woo Lee e Flynn (2011) ainda argumentam que, por vezes, para estimular a demanda em determinado porto, é feito um subsídio cruzado entre portos, diferentemente do que ocorre no Brasil, onde o senso comum diz que devem existir subsídios cruzados entre tarifas e não entre portos.

A literatura sobre governança portuária tem avançado nos últimos anos (Zhang et al., 2018). No entanto, quando se fala em ferramentas gerenciais, a literatura ainda não é conclusiva e não apresenta muitos casos aplicados ao contexto brasileiro. Tendo esse fato em mente, e a necessidade de uma efetiva gestão no setor portuário brasileiro, o objetivo deste artigo é realizar uma pesquisa qualitativa junto a 
VI CIDESPORT/2019

Congresso Internacional

de Desempenho Portuário

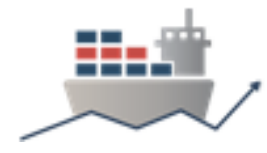

especialistas do setor portuário brasileiro para entender: (i) quais fatores afetam a competitividade dos portos, e particularmente aspectos ligados à utilização eficiente dos recursos econômicos, (ii) quais ferramentas são utilizadas e (iii) quais deveriam ser utilizadas para o efetivo gerenciamento desses fatores, confrontando-os com os caminhos apontados pela literatura. A partir disso, pretende-se determinar quais são as prioridades, em termos gerenciais, para a melhoria da gestão dos portos brasileiros.

Após esta introdução, a próxima seção apresenta a metodologia utilizada na execução do trabalho. Na seção 3, estudo aplicado, são apresentadas a descrição, análises e interpretação das entrevistas. Por fim, a quarta e última seção contempla as conclusões, incluindo recomendações de ações a serem tomadas para fortalecer a gestão dos portos.

\section{METODOLOGIA}

Segundo Voss, Tsikriktsis e Frohlich (2002) o planejamento de um estudo qualitativo possui 7 passos fundamentais: (i) Quando utilizar; (ii) Desenvolvimento do constructo; (iii) Definição dos entrevistados; (iv) Desenvolver os instrumentos de coleta; (v) Conduzir o estudo; (vi) Documentação dos dados; (vii) Levantamento de hipóteses.

No caso deste estudo, segundo Meredith (1998), o motivo que justifica a adoção da pesquisa qualitativa é: "investigação exploratória de um fenômeno que ainda não é entendido em sua totalidade". Essa justificativa vai ao encontro da falta de alinhamento encontrada na literatura de ferramentas de gestão portuária.

Para a construção do constructo foi realizada uma pesquisa na base Scopus pelos seguintes termos: Ports \& efficiency; Ports \& governance; Ports \& financial efficiency; Brazilian ports; Port governance tools; Ports \& governance models. Na sequência, foram removidos os artigos duplicados e foi realizada a leitura dos resumos, processo que removeu mais alguns artigos da base. Por fim, foi realizada a leitura dos artigos e, ao longo deste processo, outros artigos sendo incorporados. Ao final, chegou-se a uma população de 43 artigos analisados.

A partir da leitura dos artigos restantes e de discussões entre os autores, foi definido o questionário da pesquisa qualitativa, que contém 7 questões abertas, conforme Apêndice A. Optou-se por questões abertas para que os entrevistados não ficassem limitados em suas respostas e pudessem dar opiniões/percepções que não necessariamente sejam o objetivo da pergunta, a fim de levantar outros pontos a serem melhor compreendidos no setor. Na sequência é feita uma breve descrição acerca dos objetivos de cada uma das questões e seu relacionamento com o objetivo final do trabalho.

As duas primeiras questões tratam do tema competitividade sob o prisma de fatores externos à gestão da AP. Nas questões 3 a 5 são tratados os fatores internos que afetam a competitividade da AP, como eles são gerenciados e como deveriam ser gerenciados. A sexta questão está relacionada com a atração de demanda após a implementação destas melhorias.

(i) Que fatores externos (localização, acesso, mercado, etc.) afetam a competitividade de um porto?

O objetivo da pergunta inicial é levantar aspectos que não são de gestão do porto, mas que de uma forma ou de outra acabam afetando sua competitividade e eficiência. Cabe salientar que as ferramentas de gestão pouco têm a contribuir para potencializar 
VI CIDESPORT/2019

Congresso Internacional

de Desempenho Portuário

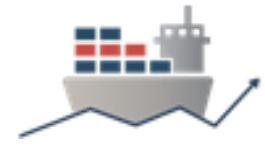

ou mitigar estes aspectos; no entanto, deve-se ter em mente estes fatores quando do desenvolvimento destas.

(ii) Como um porto faz para mitigar os efeitos negativos dos fatores externos à gestão da AP e se tornar mais competitivo?

Apesar de serem efeitos externos à gestão da AP, eventualmente alguns desses fatores podem ser monitorados pela gestão do porto. Caso os entrevistados identifiquem formas de gerenciar estes fatores, os mesmos deverão ser levados em consideração nas ferramentas de gestão.

(iii) Que fatores internos afetam a competitividade de um porto (capacidade operacional, sistemas de informação, etc.)?

O objetivo desta pergunta é levantar os fatores internos que afetam a competitividade de um porto. É importante ressaltar, aqui, que os fatores levantados nesta pergunta podem ser comparados com os fatores apontados na literatura.

(iv) Quais as ferramentas utilizadas para o gerenciamento e melhoria de um porto?

A partir da identificação dos fatores-chave para o bom desempenho do porto, esta questão tem por objetivo identificar como a gestão dos fatores internos é realizada hoje nos portos. Nesse sentido, a ideia é verificar se as ferramentas utilizadas estão alinhadas com as ferramentas identificadas na literatura.

(v) O que você faria para gerenciar os fatores internos e de que ferramentas necessitaria?

Diferentemente da questão anterior onde o objetivo é entender o status atual, nesta questão a ideia é identificar quais ferramentas 'ideais' deveriam ser utilizadas para gerenciar os fatores-chave para o desempenho e competitividade de um porto. Neste ponto, a comparação das ferramentas ditas 'ideais' com as ferramentas encontradas na literatura dá direcionamento para novos desenvolvimentos.

(vi) Até que ponto você entende que a implementação dessas melhorias irá atrair mais carga para o porto?

Após a identificação dos fatores externos e internos que afetam a competitividade de um porto, o objetivo desta questão é entender se a demanda, ou seu aumento, está relacionada com a melhoria interna do porto. Independentemente dos resultados, os portos devem buscar o incremento de eficiência, mas a identificação se sua demanda está ou não relacionada como essas melhorias terá impacto nos resultados do porto, bem como pode auxiliar a nortear a avaliação de novos investimentos.

(vii) Há mais alguma coisa que o entrevistado entende ser importante para a análise?

Esta última pergunta permite que o entrevistado complemente algumas das respostas anteriores, qualificando a coleta de informações.

A definição dos entrevistados levou em consideração a formatação do setor portuário brasileiro. A Secretaria Nacional de Portos e Transportes Aquaviários (SNPTA), antiga Secretaria Especial de Portos (SEP), é a responsável pelo planejamento do setor portuário brasileiro e definição de suas diretrizes. Já a Agência Nacional de Transportes Aquaviários (ANTAQ) é responsável pela operacionalização 
VI CIDESPORT/2019

Congresso Internacional

de Desempenho Portuário

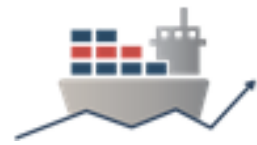

e implementação das diretrizes na SNPTA. Compete à ANTAQ monitorar, fiscalizar e regular os portos. São alvo desta regulação tanto os portos públicos quanto os Terminais de Uso Privativo (TUPs). Paralelamente a isso, encontra-se o Tribunal de Contas da União (TCU), responsável pelo julgamento das contas dos administradores públicos, ou seja, fiscaliza as contas e investimentos realizados pelos portos. O TCU possui uma Secretaria (Secretaria de Fiscalização de Infraestrutura Portuária e Ferroviária) que é responsável, dentre outras atribuições, por fiscalizar o segmento portuário. A Figura 1 apresenta como estes diferentes atores do Sistema Portuário Brasileiro estão relacionados. A pesquisa qualitativa realizada neste estudo contou com um representante de cada um destes elos, todos eles com cargo de gestão.

A operacionalização das entrevistas se deu através de contatos dos autores com essas instituições, e elas foram realizadas por Skype ${ }^{\circledR}$ e gravadas com autorização dos participantes.

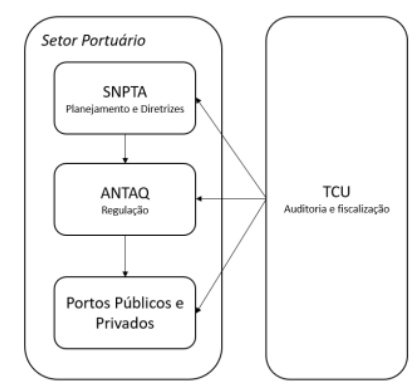

Figura 1: Atores do Sistema Portuário Brasileiro.

Fonte: Elaborado pelos autores.

O objetivo inicial do estudo era entrevistar ao menos uma pessoa do alto escalão (gerentes, diretores, ex-gerentes e ex-diretores) de cada um dos grupos destacados na Figura 1. A justificativa se dá pelo fato de que, apesar de envolvidos no mesmo setor, eles podem apresentar visões distintas, o que contribui para a formação de uma visão ampla e heterogênea dos aspectos estudados.

Após a realização das entrevistas, foi realizada sua transcrição. Na sequência, as informações foram categorizadas para análise e interpretação. Cabe salientar que a próxima seção do artigo contempla uma breve caracterização dos entrevistados, bem como a descrição, análise e interpretação das entrevistas.

O levantamento de hipóteses diz respeito à interpretação dos autores e do cruzamento das informações obtidas nas entrevistas com a pesquisa bibliográfica. No levantamento de hipóteses, ou no caso específico deste artigo, serão feitas recomendações de ações a serem executadas a fim de fortalecer a gestão no sistema portuário brasileiro.

\section{ESTUDO APLICADO}

A condução do estudo aplicado se deu através de entrevistas individuais realizadas por aplicativo de videoconferência. Todos os entrevistados permitiram que as entrevistas fossem gravadas e salientaram que suas respostas representam opiniões pessoais acerca dos questionamentos, e não versões institucionais dos Órgãos sobre as mesmas. Este fato não prejudica os resultados obtidos, visto que o objetivo foi levantar diferentes pontos de vista complementares sobre os questionamentos feitos. A fim de manter em sigilo a identidade dos entrevistados, na 
VI CIDESPORT/2019

Congresso Internacional

de Desempenho Portuário

sequência será realizada uma breve descrição de cada entrevistado, os quais serão chamados de Entrevistados 1 a 4 (E1 a E4).

O E1 trabalha na ANTAQ e já atuou em diversos setores da Agência. Possui mais de 20 anos de experiência no segmento. Já o E2 atua no TCU, e é um dos responsáveis pela fiscalização dos gestores públicos do segmento portuário. O E3 já foi presidente de uma AP e Diretor em outra. Adicionalmente, já atuou em diversos projetos relacionados ao segmento Portuário Brasileiro, tendo atuado também em outros órgãos relacionados ao setor. O E4 está vinculado à SNPTA, já atuou em um Porto e possui formação no setor Portuário. Cabe salientar que as quatro pessoas entrevistadas são técnicas, com ampla experiência no setor, contribuindo assim com suas experiências e opiniões não só no que tange às suas posições atuais como também a experiência adquirida ao longo dos anos. Cabe salientar também que, como o foco do artigo está na melhoria da gestão dos portos públicos, por este motivo não foi entrevistado nenhum gestor de porto privado.

A seguir, será realizada a transcrição dos elementos chave das entrevistas.

Questão 1- Que fatores externos (localização, acesso, mercado, etc.) afetam a competitividade de um porto?

Segundo o E1, são dois os principais fatores externos à gestão do Porto, seja ele público ou privado, que afetam sua competitividade: (i) localização, a qual é traduzida, segundo palavras do próprio entrevistado, como o mercado e (ii) acessos, sejam eles terrestres, ferroviários ou rodoviários. O E2 argumenta que os acessos aos Portos são precários, e que esse fato está relacionado à qualidade da infraestrutura. Para o E2 os acessos têm impacto na competitividade de um Porto; no entanto, existem dois aspectos ainda mais preponderantes para a competividade do Porto: a legislação e a política. Segundo o entrevistado, a legislação, por exemplo, obriga a contratação do Órgão de Gestão de Mão-Obra (OGMO), o qual pode, por vezes, afetar a competitividade do Porto. No que tange a Política, a politização da gestão portuária é apontada como algo que por vezes é nocivo ao Porto, pois as indicações não necessariamente possuem interesses republicanos.

O E3 inicia sua resposta argumentando que deveria ser feita uma distinção para as respostas em relação aos portos públicos e privados, de acordo com o status atual do setor no País. No entanto, para o E3, o "modelo deveria ser um só", e a regra geral de exploração deveria ser igual para todos os Portos. O E3 argumenta que o principal fator externo à gestão de um Porto que afeta a sua competitividade é a dificuldade em se fazer contratos com os privados. Segundo o entrevistado, o gestor público lida com as regras do direito público, as quais não são ruins, mas criam a necessidade de arrendamento de uma área (única forma de contrato). O problema é que essa forma de fazer contratos, que foi criada em 1993 quando não existia a Lei das Concessões, faz com que toda a movimentação necessite de um contrato. Para o E3, essa formatação traz consigo uma rigidez que não faz sentido. Adicionalmente, o entrevistado argumenta que os contratos de longo prazo não têm flexibilidade para movimentação de outros tipos de carga ou revisões contratuais, as quais são alvo de diversos questionamentos por parte do TCU. Para o E3, os serviços são secundários nos contratos, e como "resultado desse modelo: nos últimos 15 anos nós fizemos a média de um arrendamento por ano no país". O entrevistado diz ainda que, caso um ente privado queira fazer um contrato com uma AP, o prazo "para construir tudo direitinho, não ter nenhum problema, é de 3 a 4 anos". Por fim, o E3 argumenta que o arranjo legal do setor, de certa forma, estimula os privados a criarem seus próprios terminais ao lado dos Portos Públicos. 
O segundo fator apontado pelo E3 é que para o privado não é viável fazer um Porto se ele tiver de fazer todos os investimentos. Por isso, acaba fazendo pressão no Governo para que este faça os investimentos necessários. Segundo o E3, a figura do terminal privado surgiu porque a atual forma de condomínio não tem como ser bem gerida com a "burocracia intransponível" à qual está sujeita. Para o E3, ou se criam outras modalidades de contratos, ou as APs devem ser concedidas à iniciativa privada.

Por fim, o E4 diz que são quatro os principais fatores externos: (i) acessos, os quais necessitam de investimentos públicos em infraestrutura, (ii) a falta de integração dos órgãos intervenientes, (iii) mercado, risco de mercado, instabilidade política e demais questões econômicas e (iv) insegurança jurídica no setor. Para o E4, a insegurança jurídica precisa ser sanada para dar maior segurança ao investidor, visto que as regras têm mudado em função do Governo.

Questão 2 - Como um porto faz para mitigar os efeitos negativos dos fatores

externos à gestão da AP e se tornar mais competitivo?

Segundo o E1, a forma de mitigar a questão dos acessos é uma grande política de desapropriação de terras, visto que muitos portos estão próximos a áreas urbanas das cidades, fato que prejudica o acesso aos portos em função da impossibilidade de melhorar a infraestrutura. A questão mercadológica é definida pelo próprio mercado.

Para o E2, a questão dos acessos aquaviários deveria ser resolvida passando a responsabilidade da dragagem para os próprios terminais. O E3 disse, ao longo da entrevista, que a dragagem nos Estados Unidos, por exemplo, é realizada pelo exército, visto que é uma atividade que todos sabem que não dá retorno. No que tange a legislação e política, o E2 acredita que deveria ser realizado um esforço para reunir os atores do setor portuário para tentar mudar a legislação e diminuir as interferências políticas no setor (novo marco legal e regulatório).

O E3 argumenta que, para a correção dos problemas relacionados à dificuldade em fazer contratos, deve-se conceder a exploração das atividades portuárias. Segundo esse entrevistado, o qual já dirigiu um Porto, um trabalho entre judiciário, executivo, legislativo e TCU para criar alternativas contratuais para que se tenha dinamismo ao fazer contratos é necessário caso se queira dar uma chance para os portos públicos. Com a relação à falta de viabilidade de portos privados, cita que no mundo todo se clusterizam portos e no Brasil se pulverizam portos "como se fossem padarias".

O E4, que atua na SNPTA, diz que é impossível sair do status atual caso não haja melhoria de gestão dentro dos portos. Segundo ele, "o governo tem, de alguma forma, investido em qualificação de pessoal, apertando regras de gestão das estatais, mas ainda é incipiente". Segundo o entrevistado, o gestor atende a legislação, mas, por vezes, não tem visão de mercado e não utiliza ferramentas de gestão a favor da empresa.

Questão 3 - Que fatores internos afetam a competitividade de um porto (capacidade operacional, sistemas de informação, etc.)?

No que tange aos fatores internos que afetam a competitividade de um Porto, o E1 argumenta que "o grande problema hoje do setor portuário público, agora está melhorando, mas não $100 \%$, são os indicados políticos com interesses não republicanos que só querem tirar dinheiro do Porto". O E1 acrescenta ainda que o quadro de funcionários de algumas APs é muito grande, e uma vez que a empresa está vinculada à União, "o diretor fica muito amarrado" para resolver esta e outras questões relacionadas à legislação e contratações. Falando em termos operacionais 
VI CIDESPORT/2019

Congresso Internacional

de Desempenho Portuário

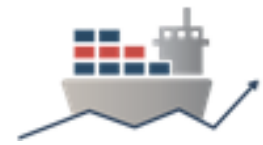

e sistemas de informação, o E1 diz que investimentos em sistemas de informação, trabalho comercial e manutenção programada são formas de melhorar a operação de um porto.

O E2 diz que para um porto ser competitivo é necessário calado adequado, capacitação de mão-de-obra, acessos de qualidade e profissionalização da gestão. De acordo com a percepção do E2, os terminais privados têm mais flexibilidade para contratações, e sua gestão é mais profissional.

Para o E3, o alto custo de mão-de-obra, a falta de dinheiro da AP e a baixa autonomia fazem com que a regulação aumente. Tendo em vista seu mau resultado e a grande quantidade de obrigações legais, a AP tem cada vez menos dinheiro e é cada vez menos eficiente. De forma geral, o E3 entende que a raiz dos problemas é a dificuldade em fazer contratos. Já para o E4, a questão dos sistemas de informação é crítica. Segundo sua visão, atualmente existe um excesso de burocracia. A falta de sistemas integrados também complica a gestão financeira. Adicionalmente, o E4 vê que um melhor planejamento da capacidade portuária, em termos setoriais, é necessário para o aumento da eficiência. Segundo o E4, "em algum momento se concedeu muitos portos, que acabaram virando especulação imobiliária ao invés de gerar investimentos". Também disse que é preciso "Planejar melhor a capacidade do setor como um todo".

Questão 4 - Quais as ferramentas utilizadas para o gerenciamento e melhoria de um porto?

Segundo o E1, em termos de gestão são utilizados indicadores como: container/hora, tonelada/hora, conservação média, movimento/hora. Segundo o E1, que atua na ANTAQ, "o porto infelizmente não sabe a quantidade movimentada. Quem passa a informação é o arrendatário". Segundo esse entrevistado, a fiscalização das APs é amostral. Segundo o E1, "o grande problema é que no Brasil ninguém confere". O E2 inicia sua resposta da seguinte forma: "dentro do porto público não sei se se usa muita coisa". O E2 diz que conhecer seus custos e suas tarifas deveria ser o ponto de partida. Segundo o entrevistado, "a Companhia de Docas do Espírito Santo (CODESA) até tem utilizado estas ferramentas, outros deveriam utilizar". Segundo o E2, a necessidade de ferramentas de gestão é gritante. Para o entrevistado, "a aparência que se tem é que na maioria dos portos públicos têm o discurso de modernização, de querer melhorar, mas que fica só no discurso". Segundo o E2, o papel de exigir a profissionalização da Gestão "nem seria da ANTAQ, e sim do Ministério". O E3, de forma sucinta, diz que hoje os Portos não têm ferramentas de gestão, pois não tem dinheiro e falta integração entre órgãos e sistemas de informação.

Para o E4, de modo geral, os Portos só possuem as ferramentas de gestão mandatórias (planejamento estratégico e Plano de Desenvolvimento e Zoneamento PDZ). Segundo o entrevistado, um plano comercial é algo que poucos Portos têm. Segundo o entrevistado, os Portos deveriam trabalhar com os arrendatários para buscar integração e formas de 'vender' o Porto. Segundo ele, no exterior, os Portos articulam-se muito bem com os arrendatários, mas aqui existe muita desconfiança nesta relação. Para esse entrevistado, em termos de ferramentas de gestão, os portos estão muito presos na burocracia e nas ferramentas obrigatórias, e que poucos pensam 'fora da caixa'. E4 acrescenta que existe pouca utilização de ferramentas de mercado e que o porto de Paranaguá possui um bom sistema de gestão de contratos e movimentações. 
VI CIDESPORT/2019

Congresso Internacional

de Desempenho Portuário

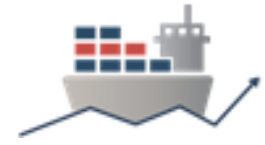

Questão 5 - O que você faria para gerenciar esses fatores e de que ferramentas necessitaria?

Segundo o E1, "o ponto mais importante é integração de informações operacionais, contabilidade e financeiro. Hoje essa integração é primordial”. A partir daí, a apropriação dos custos e a integração ao plano de contas permitirá "no futuro fazermos um ABC (Actitivty-Based Costing) integrado com as receitas". Adicionalmente, sugere um sistema informatizado com os cadastros de todos os contratos e suas cláusulas. Segundo ele, a adoção destas ações, de forma integrada e que tenha um padrão para todos os portos, permitirá comparabilidade e identificação de melhores práticas.

Já o E2 diz que é necessário fazer um benchmark internacional sobre ferramentas de gestão. Além disso, um planejamento setorial mais forte é necessário. Segundo o E2, tem-se uma grande preocupação com a questão tarifária, a qual impacta diretamente na auto-sustentabilidade dos portos. Segundo a visão do E2, falta transparência nos números. Adicionalmente, argumenta que "tem-se entendido que o modelo tarifário está ruim porque existe subsídio cruzado". Por fim, diz que "só consegue regular se conhecer o custo. Com o custeio fica, no mínimo mais transparente".

Para o E3, a primeira ferramenta é um cardápio de contratos que podem ser feitos. O segundo ponto apontado seria a criação de um órgão único para centralizar o desenvolvimento das atividades, ou para fazer um 'órgão confiar no outro'. Segundo o entrevistado, "a Receita não confia na ANVISA, e assim sucessivamente". A relatada falta de confiança gera, na opinião do entrevistado, burocracia excessiva. Para tanto, sugere a adoção de uma ferramenta de compartilhamento de informações via blockchain. Para o entrevistado, a falta de integração e da visão de condomínio prejudica a eficiência da operação, cria subsídios maiores para os que menos precisam e burocratiza excessivamente o setor. Por fim, argumenta que a estrutura tarifária é complexa e que não permite ao porto cobrar por situações não-padrão. Segundo o entrevistado, em Roterdã "se ocorreu algo diferente do padrão, precifica e cobra. Aqui não, se ocorre algo desse tipo, não tem previsão, se quiser cobrar tem que responder ao Tribunal de Contas. Acaba não cobrando por várias coisas". A falta de autonomia da AP é apontada como algo muito nocivo ao desenvolvimento do setor.

Já para o E4, a primeira questão a ser resolvida é a de pessoal nas companhias Docas. Há necessidade de capacitação e renovação. O segundo ponto é equacionar a questão da regulação, visto que é muito caro manter tudo dentro das exigências. Segundo o E4, "todos os órgãos querem o ótimo, e isso encarece muito as operações". A integração entre os intervenientes é vista como chave para a melhor integração. A necessidade de ranqueamento de projetos de investimentos também é citada como algo que necessita ser feita. Segundo o E4, "os portos que mais recebem investimentos são os que tiveram as menores taxas de crescimento". Por fim, o entrevistado comenta que as atuais ferramentas de governança não têm efetividade, e que é necessária a "responsabilização em casos onde houve danos ao erário público".

Questão 6 - Até que ponto você entende que a implementação dessas melhorias irá atrair mais carga para o porto?

Segundo o E1, a elasticidade se dá em função do custo total do transporte. $\mathrm{Na}$ parte de commodities, o acesso tem grande impacto. Em containers, há maior elasticidade, e, se os valores da Tabela 1 (referente a estrutura tarifária dos portos) forem menores, conseguirá atrair mais carga. Para o E1, "atração de carga no Porto 
VI CIDESPORT/2019

Congresso Internacional

de Desempenho Portuário

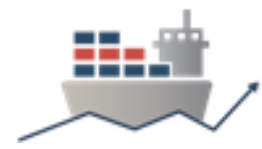

é a longo prazo. Boa gestão e bons acessos". A resposta do E4 está alinhada com a do E1, ou seja, depende do tipo e do valor agregado da carga. Segundo o E2, no médio longo e prazo a demanda é elástica, pois segundo ele "tem muita demanda reprimida, e se você tornar os portos mais eficientes a chance de eles ganharem mais cargas é considerável".

Para o E3, o planejamento setorial é fundamental. Segundo esse entrevistado, o planejamento da capacidade deve se dar em etapas: (i) melhorar a operação; ampliar a capacidade do porto (só amplia o porto se estiver no limite da eficiência e da capacidade operacional); (ii) construção um novo porto. O E3 diz que o planejamento é fundamental para organizar o investimento.

Questão 7 - Há mais alguma coisa que o entrevistado entende ser importante para a análise?

Por fim, foi aberto o espaço para que cada entrevistado pudesse acrescentar algo que julgasse importante e que ainda não havia comentado. Segundo o E1, a operação portuária no Brasil é comparada ao primeiro mundo. Já o E2 salientou, uma vez mais, que a insegurança jurídica traz insegurança ao investidor que "tudo no porto público acaba sendo judicializado". O E4 acrescentou que uma das dificuldades encontradas no setor é a resistência a mudanças por parte dos quadros das companhias Docas e as várias tentativas infrutíferas de implementação de ferramentas.

As Tabelas 1 e 2 apresentam a consolidação das respostas dos entrevistados. A Tabela 1 apresenta os principais aspectos externos citados, e a Tabela 2 as principais necessidades em termos de gestão.

\begin{tabular}{|c|c|}
\hline $\begin{array}{c}\text { Aspectos externos a serem } \\
\text { considerados }\end{array}$ & Número de citações \\
\hline Acessos ao porto & 3 \\
\hline Conjunto legal & 3 \\
\hline Mercado & 2 \\
\hline Questões Políticas & 2 \\
\hline
\end{tabular}

Tabela 2: Número de aspectos externos citados nas entrevistas.

Fonte: Elaborado pelos autores.

\begin{tabular}{|c|c|}
\hline $\begin{array}{c}\text { Aspectos gerenciais a serem } \\
\text { desenvolvidos }\end{array}$ & Número de citações \\
\hline Questões tarifárias & 3 \\
\hline Controle de custos & 3 \\
\hline Integração de sistemas de \\
informação & 2 \\
\hline Ranqueamento de projetos & 1 \\
\hline Sistema de contratos & 1 \\
\hline Regulação & 1 \\
\hline
\end{tabular}

Tabela 3:Número de aspectos gerenciais a serem desenvolvidos citados nas entrevistas.

Fonte: Elaborado pelos autores.

\subsection{Análise e Interpretação}

A descrição das entrevistas realizadas nas seções anteriores evidenciou que os fatores externos e internos acabam interagindo e afetando a eficiência dos portos. 
VI CIDESPORT/2019

Congresso Internacional

de Desempenho Portuário

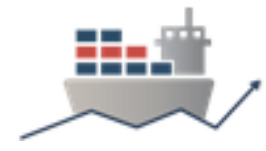

Por este motivo, a análise e interpretação das entrevistas realizadas se dará em 2 níveis: setorial e gerencial. Por análise setorial entende-se o contexto mais amplo do regramento, conjunto de leis e alinhamento entre órgãos todos eles externos à AP. Já a análise gerencial diz respeito aos fatores que devem ser gerenciados através de ferramentas de gestão pelo porto, seguindo a classificação de Zhang et al. (2019).

\subsubsection{Análise Setorial}

Zhang et al. (2018), quando estudaram quem faz a governança portuária e quem é governado, chegaram à conclusão de que, via de regra, organizações governamentais fazem a governança e que os Portos, sejam eles públicos ou privados, são alvos da governança. Apesar de, em boa parte do mundo, essa situação ser respeitada, existem diferenças entre as formas de atuação e dos avanços recentes na legislação.

Segundo Zhang et al. (2018), os avanços recentes na legislação de países como Bélgica, Holanda e Portugal são no sentido de centralizar o papel de quem faz a governança, mas concedendo maior autonomia para as APs. Já no Brasil, conforme o estudo supracitado, o papel de quem governa é centralizado, mas a autonomia das APs é pequena. Segundo se pôde comprovar na descrição das entrevistas, a falta de agilidade dos portos brasileiros em fazer contratos e gerar receitas está minando sua eficiência. Dos quatro entrevistados, todos citaram como fatores externos à gestão da AP e que afetam a sua eficiência, Legislação, Marco Regulatório e Marco Legal.

Esse fato leva a crer que, apesar da legislação do setor estar caminhando para portos do tipo landlord, a forma como esse processo está ocorrendo no Brasil não tem sido eficiente, visto que para que o mesmo tenha sucesso, a dinamicidade e adaptabilidade ao mercado são fundamentais (Chen, Pateman e Sakalayen, 2017). Outro ponto levantado diz respeito à politização do setor, ainda que seja reconhecida uma melhora deste aspecto pelos entrevistados. O alto grau de politização observado talvez justifique a falta de autonomia da AP. Nesse mesmo sentido, todos os entrevistados entendem que a gestão dos portos precisa ser profissionalizada. Apesar disso, as baixas taxas de ocupação dos portos e a percepção de que se tem uma demanda reprimida parecem demonstrar que algo precisa ser revisto.

Outro aspecto citado por todos os entrevistados diz respeito ao planejamento de forma ampla, seja o planejamento da capacidade do setor e da forma de condução de investimentos e concessão de novos portos, bem como dos acessos aos portos, sejam eles hidroviários, rodoviários ou ferroviários. Nesse sentido, quando são realizados estudos de DEA buscando ranquear portos em relação à sua eficiência, independentemente dos inputs e outputs a serem considerados, há que se levar em consideração que determinado porto pode não estar desempenhando bem em função dos seus acessos, mercado consumidor e que, nem por isso, apesar do DEA indicar, ele é menos eficiente internamente do que outros portos. Para que as análises pudessem ser conclusivas, seria necessário excluir ou isolar essas variáveis de contorno.

Um terceiro e último grande fator setorial que restringe a eficiência dos portos destacado pelos entrevistados foi a sobreposição de funções entre os diversos órgãos anuentes. É necessário salientar que, apesar de serem órgãos diferentes, boa parte dos mesmos pertence à União. Segundo o E4, hoje "todos os órgãos querem o ótimo, e isso encarece muito as operações". Sendo assim, eles deveriam fazer esforços para otimizar suas intervenções e não em realizar intervenções ótimas, tendo em vista a otimização das despesas e a melhoria na operação. O compartilhamento das informações via blockchain, conforme sugestão de um dos entrevistados, pode ser o 
VI CIDESPORT/2019

Congresso Internacional

de Desempenho Portuário

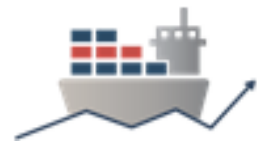

primeiro passo nessa discussão. No entanto, uma discussão mais ampla e integrada entre os diversos órgãos e stakeholders, tendo em vista a melhoria operacional para os clientes do porto e para o cumprimento das exigências legais, faz-se necessária.

Sendo assim, em termos de análise setorial, existem três grandes aspectos a serem melhorados. O primeiro deles diz respeito ao conjunto legal do setor. $\mathrm{O}$ segundo diz respeito ao planejamento de capacidade e de investimento do setor. Já o terceiro diz respeito ao alinhamento entre os órgãos reguladores. A Figura 2 apresenta os três aspectos, seus potenciais desdobramentos e envolvidos no processo de mudança. Salienta-se que o entendimento é de que estes aspectos devem ser atacados priorizados da esquerda para a direita. Todas estas alterações e melhorias devem ter em mente que, segundo o E3, "precisamos mudar o foco dos portos para os serviços". Entende-se como foco nos serviços a visão do cliente final.

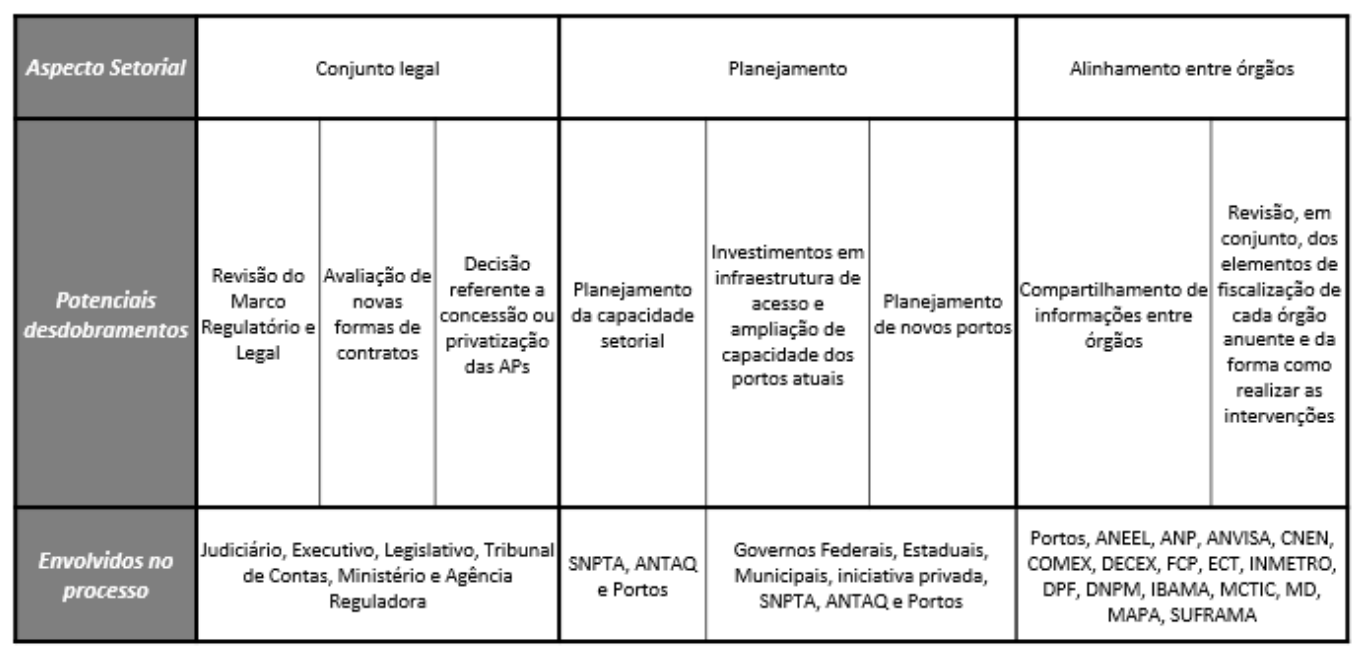

Figura 2: Ações setoriais a serem avaliadas.

Fonte: Elaborado pelos autores.

\subsubsection{Análise gerencial}

Zhang et al. (2019) classificaram as ferramentas de governança em 3 níveis: institucional, estratégico e gerencial. Entende-se que os níveis institucional e estratégico referem-se a questões setoriais, ou de contorno aos Portos. Apesar desses fatores terem grande impacto no cotidiano dos portos e também em sua eficiência, as APs pouco podem agir nesse sentido. Sendo assim, a análise gerencial diz respeito às ferramentas utilizadas para gerenciamento e melhoria de um porto. Entende-se também que todas as ações do nível setorial que venham a ser realizadas no intuito de aumentar a eficiência dos portos são benéficas; no entanto, a implementação de ferramentas gerenciais deve ser realizada independentemente das condições de contorno. Cabe salientar que, no nível gerencial, não serão discutidos aspectos relacionados a politização do setor, visto que estes fatores poderão ser resolvidos no contexto setorial e que as ferramentas pouco podem fazer sobre esta questão a não ser garantir a transparência da gestão da organização.

As sete ferramentas gerenciais identificadas por Zhang et al. (2019), conforme Tabela 1, são: (i) precificação, (ii) concessão, (iii) relacionamento de clientes, (iv) monitoramento e mensuração, (v) controle regulatório, (vi) gestão da segurança e (vii) 
VI CIDESPORT/2019

Congresso Internacional

de Desempenho Portuário

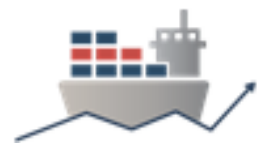

tecnologia da informação e comunicação. Os autores classificaram as ferramentas e identificaram qual o objetivo de cada uma. No entanto, para que se possa determinar prioridades e ações a serem realizadas, entender o relacionamento entres elas é fundamental. A Figura 3 apresenta a visão dos autores sobre a integração dos aspectos setoriais com as ferramentas gerenciais, bem como seus principais interrelacionamentos.

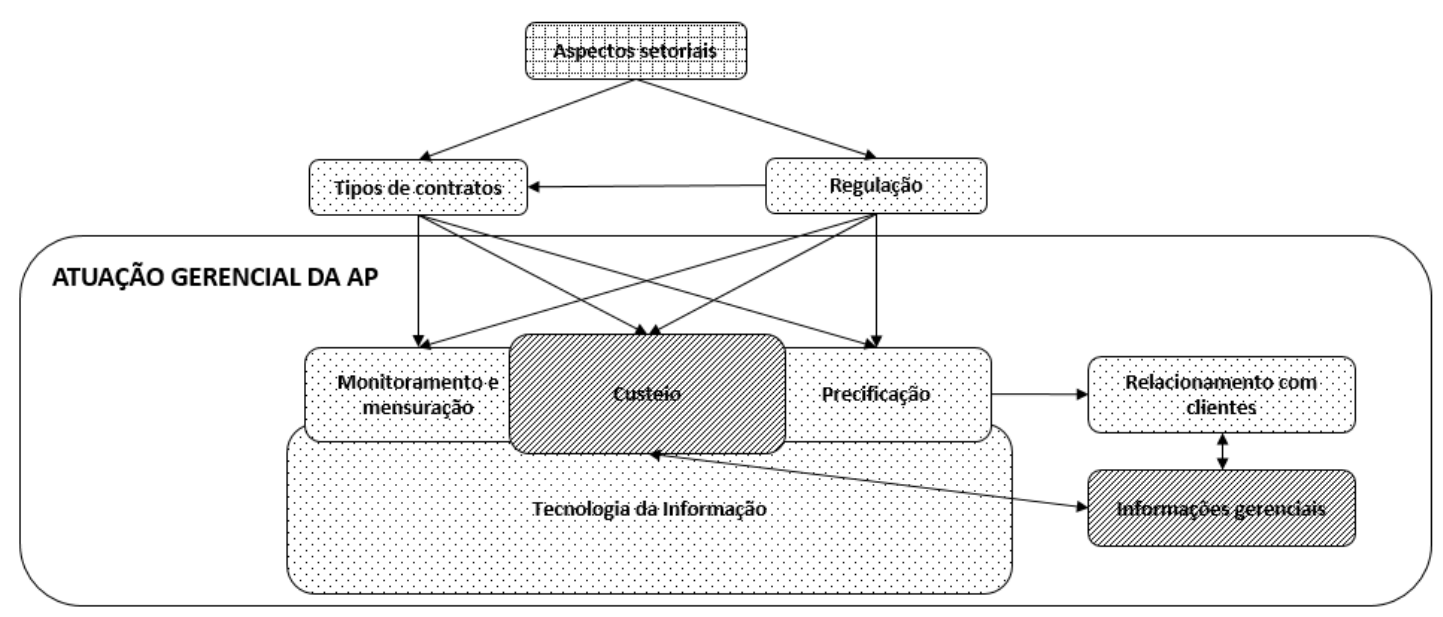

Figura 3: Integração dos aspectos gerenciais ao Sistema Portuário Brasileiro.

Fonte: Elaborado pelos autores.

Na Figura 3, o quadro de 'Aspectos setoriais' está com formatação diferenciada visto que já foi analisado na seção anterior. Os quadros pontilhados representam as ferramentas citadas por Zhang et al. (2019), exceto pelo fato de que se entende que a ferramenta de 'Gestão da Segurança' é uma dimensão das ferramentas de 'Monitoramento e Mensuração'. A ferramenta de concessão, foi reclassificada para 'Tipos de contratos' e corresponde ao anseio do E3 referente à disponibilidade de um cardápio de contratos. Adicionalmente, entende-se que a ferramenta de 'monitoramento e mensuração' engloba a gestão das Operações do Porto.

A dimensão de 'Custeio', com hachuras, foi incorporada na análise, uma vez que suporta as decisões estratégicas de precificação e reajustes, além de contribuir para o monitoramento e mensuração dos processos e contratos e 'Informações Gerenciais' não contemplados na classificação de Zhang et al. (2019). Além disto, a utilização de 'Informações Gerenciais' é fundamental para trazer uma visão extra contábil, extra regulatória à gestão dos portos, contribuindo assim para o aprimoramento da relação com os clientes com base em informações operacionais e econômicas relevantes.

Entende-se, portanto, que dados os aspectos setoriais citados na seção anterior são definidos os objetivos e formas de regulação bem como as formas de estruturação de contratos. A regulação, por sua vez, dá-se em aspectos operacionais, ambientais, de segurança e outros, os quais são gerenciados pela AP através da mensuração e monitoramento de seus processos, sejam eles administrativos ou operacionais.

Cabe ainda à Regulação a definição da estrutura tarifária, concessão de reajustes nas tarifas, concepção de uma contabilidade padrão, bem como os padrões de alocação dos custos para as Tabelas tarifárias. Apesar disso, não diz como cada Porto deve fazer para operacionalizar essas regras. 
Durante as entrevistas ficou claro que as principais necessidades gerenciais dos portos individualmente e como um todo são: integração de informações internas e entre órgãos anuentes, padronização das informações geradas por cada porto, transparência e confiabilidade das informações e questões relacionadas a pessoal. Nesse sentido, o E1 comentou que certa vez uma pessoa relacionada com a operação de um terminal portuário teria dito: "Sou uma empresa de informática que por acaso movimenta container". Entende-se então que a padronização de informações e a sistematização destas em um sistema de informação é fundamental para que se possa atingir tais objetivos. Apesar disso, Sistemas de Informação exigem altos investimentos e, por vezes, não se avalia o benefício que a informação irá gerar. Sendo assim, é necessário um censo de priorização na implementação destes sistemas e melhoria de bases de dados. De acordo com o E1, "o ponto mais importante é a integração de informações operacionais, contabilidade e financeiro. Hoje essa integração é primordial". Cabe salientar que as ferramentas de 'Tecnologia da Informação'(TI) são entendidas como ferramentas de apoio fundamentais, mas não uma ferramenta fim.

A ferramenta 'Informações Gerenciais' foi classificada de forma isolada em relação a 'Tecnologia da Informação' pois entende-se que TI têm por função prover a infraestrutura e meios de coleta de dados para 'Monitoramento e Mensuração', 'Precificação' e 'Custeio'. A partir da coleta destes dados e integração das ferramentas, as informações gerenciais são geradas e analisadas com o intuito de melhorar a eficiência do Porto.

As ferramentas de 'Monitoramento e Mensuração', as quais estão relacionadas à melhoria de processos, função controle e transparência necessitam dos sistemas de TI para serem geradas em tempo real e para que tenham confiabilidade. De forma análoga às ferramentas de $\mathrm{TI}$, é necessário um censo de priorização para definir (i) o que monitorar, (ii) para que objetivo e (iii) qual o benefício. $\mathrm{O}$ monitoramento e mensuração, por si sós, geram indicadores de desempenho, mas estão descolados da análise de resultados.

Nas ferramentas citadas por Zhang et al. (2019), precificação é definida como "formação da estrutura tarifária e precificação". Cabe salientar que a formação/definição da estrutura tarifária é papel da Agência Reguladora. No entanto, o processo de precificação deve ser realizado pela AP. Para tanto, é necessário que se conheça o custo de execução de cada serviço.

Segundo o E2, "tem-se entendido que o modelo tarifário está ruim porque existe subsídio cruzado". Por fim diz: "só consegue regular se conhecer o custo. Com o custeio fica, no mínimo mais transparente". Já o E3 argumenta que a estrutura tarifária é complexa e não permite ao porto cobrar por situações não-padrão. A implementação de um sistema de custeio pode auxiliar na discussão da política e da forma de tarifação. Salienta-se que um sistema de custeio tem por função capturar informações financeiras, contábeis, operacionais das diferentes áreas da organização e tratá-las de forma a gerar informações gerenciais econômicas para apoio à tomada de decisão. Segundo o E1, após a implementação da contabilidade padrão, "no futuro faremos um ABC (Actitivty-Based Costing) integrado com as receitas". Apesar disso, o E4 adverte que "todos os órgãos querem o ótimo, e isso encarece muito as operações". Sendo assim, caso se avance por esse caminho, deve-se atentar para o nível de detalhamento do sistema a ser desenvolvido.

A partir do entendimento de seus processos e por consequência de seus custos, as APs poderão adotar estratégias comerciais específicas, terão comparabilidade e rastreabilidade de seus custos, garantindo assim padrão, 
VI CIDESPORT/2019

Congresso Internacional

de Desempenho Portuário

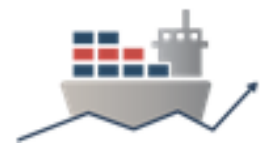

integração de informações e confiabilidade das mesmas, anseios estes citados pelos entrevistados. Ressalta-se também que, de posse de informações do sistema de custeio, comparação dos custos com as receitas, análises de efetividade e agregação de valor por atividade, as APs terão um grande volume de informações gerenciais para otimizar seus processos, repensar sua forma de atuação, discutir preços e reajustes, avaliar a terceirização ou não de atividades, modelos de concessão, modelos de contratos, priorizar investimentos, definição de estratégia comercial, etc. Nesse contexto, entende-se que o primeiro passo para a melhoria da gestão dos portos passa pela implementação de um sistema que consolide as informações operacionais, financeiras e contábeis a fim de subsidiar os gestores com informações técnicas e confiáveis para apoio à tomada de decisão.

\section{CONCLUSÕES}

Quer seja por se tratarem de empreendimentos de capital intensivo (Tae-Woo Lee e Flynn, 2011; Tovar e Wall, 2019), quer seja pelas recentes mudanças regulatórias no setor portuário (Brooks, 2017; Brooks, Cullinane e Pallis, 2017; Beuren et al., 2018), a literatura sobre questões relacionadas à eficiência (Lam e Notteboom, 2014; Chen e Lam, 2018) e governança portuária (Vieira, Kliemann Neto e Amaral, 2014; Wilmsmeier e Monios, 2016; Brooks, Cullinane e Pallis, 2017; Chen, Pateman e Sakalayen, 2017; Zhang et al., 2019) têm aumentado. Apesar dos consideráveis avanços, a literatura sobre ferramentas gerenciais aplicadas nos portos ainda não é conclusiva e não apresenta muitos casos aplicados ao contexto brasileiro. Some-se a isso a necessidade de gestão nos portos brasileiros.

Dado esse contexto, este artigo apresentou uma pesquisa qualitativa com especialistas do setor portuário brasileiro, identificando os fatores afetam a competitividade dos portos, as ferramentas utilizadas e aquelas que deveriam ser utilizadas para o efetivo gerenciamento desses fatores.

No âmbito setorial, foram destacados três principais aspectos e desdobramentos a serem executados. Os aspectos destacados foram: reestabelecer o marco legal do setor, fortalecer seu planejamento e alcançar sinergias entre órgãos anuentes. Já no âmbito gerencial, constatou-se a necessidade de ferramentas de gestão para produzir e permitir a análise de informações gerenciais. Nesse sentido, destaca-se a necessidade de um sistema que faça a "integração de informações operacionais, contábeis e financeiras", conforme afirmou o E1. Nesse sentido, sugerese como uma primeira ação de cunho gerencial a implementação de um sistema integrado de custeio para garantir a transparência e fortalecer a gestão dos portos públicos brasileiros.

\section{REFERÊNCIAS}

ANTAQ, http://web.antaq.gov.br/ANUARIO/, 2019. Acesso em 20/06/2019.

BALTAZAR, Ramon; BROOKS, Mary R. Port governance, devolution and the matching framework: a configuration theory approach. Research in Transportation Economics, v. 17, p. 379-403, 2006.

BANDARA, Yapa Mahinda; NGUYEN, Hong-Oanh; CHEN, Shu-Ling. Determinants of port infrastructure pricing. The Asian Journal of Shipping and Logistics, v. 29, n. 2, p. 187-206, 2013. 
VI CIDESPORT/2019

Congresso Internacional

de Desempenho Portuário

BEUREN, Marcelo Müller et al. On measuring the efficiency of Brazilian ports and their management models. Maritime Economics \& Logistics, v. 20, n. 1, p. 149168, 2018.

BROOKS, Mary R.; CULLINANE, Kevin. Governance models defined. Research in transportation economics, v. 17, p. 405-435, 2006.

BROOKS, Mary R. A new direction or stay the course? Canada's port-specific challenges resulting from the port reform program of the 1990s. Research in Transportation Business \& Management, v. 22, p. 161-170, 2017.

BROOKS, Mary R.; CULLINANE, Kevin PB; PALLIS, Athanasios A. Revisiting port governance and port reform: A multi-country examination. Research in Transportation Business \& Management, n. 22, p. 1-10, 2017.

CEPOLINA, Sara; GHIARA, Hilda. New trends in port strategies. Emerging role for ICT infrastructures. Research in Transportation Business \& Management, v. 8, p. 195-205, 2013.

CHEN, Hsiao-Chi; LIU, Shi-Miin. Optimal concession contracts for landlord port authorities to maximize traffic volumes. Maritime Policy \& Management, v. 42, n. 1, p. 11-25, 2015.

CHEN, Peggy Shu-Ling; PATEMAN, Hilary; SAKALAYEN, Quazi. The latest trend in Australian port privatisation: Drivers, processes and impacts. Research in Transportation Business \& Management, v. 22, p. 201-213, 2017.

CHEN, Chen; LAM, Jasmine Siu Lee. Sustainability and interactivity between cities and ports: a two-stage data envelopment analysis (DEA) approach. Maritime Policy \& Management, v. 45, n. 7, p. 944-961, 2018.

CHENG, Jiannan; YANG, Zhongzhen. The equilibria of port investment in a multi-port region in China. Transportation Research Part E: Logistics and Transportation Review, v. 108, p. 36-51, 2017.

COSTA, Eduardo Fagundes; MEZA, Lidia Angulo; ROBOREDO, Marcos Costa. A DEA model to evaluate Brazilian container terminals. RAIRO-Operations Research, v. 52, n. 3, p. 743-754, 2018.

COTO-MILLÁN, Pablo et al. Public regulation and technical efficiency in the Spanish Port Authorities: 1986-2012. Transport Policy, v. 47, p. 139-148, 2016.

DE LANGEN, Peter W.; VAN DER LUGT, Larissa M. Institutional reforms of port authorities in the Netherlands; the establishment of port development companies. Research in Transportation Business \& Management, v. 22, p. 108113, 2017.

ESKI, Yarin. The war on meaninglessness: A counter-terrorist self through an absent terrorist other. Ethnography, v. 17, n. 4, p. 460-479, 2016. 
VI CIDESPORT/2019

Congresso Internacional

de Desempenho Portuário

FARRELL, Sheila. The ownership and management structure of container terminal concessions. Maritime Policy \& Management, v. 39, n. 1, p. 7-26, 2012.

FERRARI, Claudio; PAROLA, Francesco; TEI, Alessio. Governance models and port concessions in Europe: Commonalities, critical issues and policy

perspectives. Transport Policy, v. 41, p. 60-67, 2015.

FERRETTI, Marco et al. Strategic monitoring of port authorities activities: Proposal of a multi-dimensional digital dashboard. Production Planning \& Control, v. 28, n. 16, p. 1354-1364, 2017.

GOBBI, Clarice Neffa et al. Efficiency in the environmental management of plastic wastes at Brazilian ports based on data envelopment analysis. Marine Pollution Bulletin, v. 142, p. 377-383, 2019.

GÜNER, Samet. Incorporating value judgments into port efficiency measurement models: insights from Turkish ports. Maritime Economics \& Logistics, v. 20, n. 4, p. 569-586, 2018.

JULIEN, Shelly-Ann; COWIE, Jonathan; MONIOS, Jason. Efficiency, productivity and returns to scale in ports: a comparison of data envelopment analysis and econometric estimation with application to Caribbean Small Island Developing States. Maritime Economics \& Logistics, p. 1-26, 2018.

LAM, Jasmine Siu Lee; NOTTEBOOM, Theo. The greening of ports: a comparison of port management tools used by leading ports in Asia and Europe. Transport Reviews, v. 34, n. 2, p. 169-189, 2014.

LAMBROU, Maria A.; PALLIS, Athanasios A.; NIKITAKOS, Nikitas V. Exploring the applicability of electronic markets to port governance. International Journal of Ocean Systems Management, v. 1, n. 1, p. 14-30, 2008.

LUO, Jack Xunjie et al. Application of ABC for the cost management in container terminal. In: 2009 International Conference on Information Management, Innovation Management and Industrial Engineering. IEEE, p. 349-352, 2009.

MEREDITH, Jack. Building operations management theory through case and field research. Journal of operations management, v. 16, n. 4, p. 441-454, 1998.

MONIOS, Jason. Port governance in the UK: Planning without policy. Research in Transportation Business \& Management, v. 22, p. 78-88, 2017.

NOTTEBOOM, Theo. Concession agreements as port governance tools. Research in Transportation Economics, v. 17, p. 437-455, 2006.

NOTTEBOOM, Theo E.; PALLIS, Athanasios A.; FARRELL, Sheila. Terminal concessions in seaports revisited. 2012.

PARK, Yong Shin et al. Benchmarking environmental efficiency of ports using data mining and RDEA: the case of a US container ports. International Journal of Logistics Research and Applications, v. 22, n. 2, p. 172-187, 2019. 
VI CIDESPORT/2019

Congresso Internacional

de Desempenho Portuário

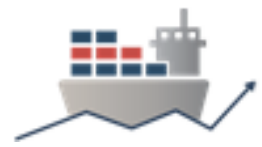

PENG, Zixuan et al. Intermodal transportation of full and empty containers in harborinland regions based on revenue management. European Transport Research Review, v. 11, n. 1, p. 7, 2019.

QU, Chenrui; WANG, Grace WY; ZENG, Qingcheng. Modelling port subsidy policies considering pricing decisions of feeder carriers. Transportation Research Part E:

Logistics and Transportation Review, v. 99, p. 115-133, 2017.

SCHØYEN, Halvor et al. Measuring the contribution of logistics service delivery performance outcomes and deep-sea container liner connectivity on port

efficiency. Research in Transportation Business \& Management, v. 28, p. 66-76, 2018.

SOROUR, Karim; ABDUL-MAGEED, Loay. Enabling better port governance in developing countries: The role of information technology. In: ICTs in Developing Countries. Palgrave Macmillan, London, 2016. p. 171-189.

TAE-WOO LEE, Paul; FLYNN, Matthew. Charting a new paradigm of container hub port development policy: The Asian doctrine. Transport Reviews, v. 31, n. 6, p. 791806, 2011.

TOVAR, Beatriz; WALL, Alan. Are larger and more complex port more productive? An analysis of Spanish port authorities. Transportation Research Part A: Policy and Practice, v. 121, p. 265-276, 2019.

VAN DE VOORDE, Eddy; VERHOEVEN, Patrick. Port governance and policy changes in Belgium 2006-2016: a comprehensive assessment of process and impact. Research in transportation business \& management, v. 22, p. 123-134, 2017.

VIEIRA, Guilherme Bergmann Borges; KLIEMANN NETO, Francisco José; AMARAL, Fernando Gonçalves. Governance, governance models and port performance: A systematic review. Transport Reviews, v. 34, n. 5, p. 645-662, 2014.

VERHOEVEN, Patrick. A review of port authority functions: towards a renaissance?. Maritime Policy \& Management, v. 37, n. 3, p. 247-270, 2010.

VOSS, Chris; TSIKRIKTSIS, Nikos; FROHLICH, Mark. Case research in operations management. International Journal of Operations \& Production Management, v. 22, i. 2, p. 195-219, 2002.

WILMSMEIER, Gordon; MONIOS, Jason. Institutional structure and agency in the governance of spatial diversification of port system evolution in Latin

America. Journal of Transport Geography, v. 51, p. 294-307, 2016.

$\mathrm{XIAO}$, Yibin et al. An analysis of the dynamics of ownership, capacity investments and pricing structure of ports. Transport Reviews, v. 32, n. 5, p. 629-652, 2012. 
VI CIDESPORT/2019

Congresso Internacional

de Desempenho Portuário

ZHANG, Jihua. Quasi-landlord port financing in China: Features, practice and a contract theory analysis. Transportation Research Part A: Policy and Practice, v. 89, p. 73-88, 2016.

ZHANG, Qiang et al. Who governs and what is governed in port governance: A review study. Transport Policy, v. 64, p. 51-60, 2018.

ZHANG, Qiang et al. Port governance revisited: How to govern and for what purpose?. Transport Policy, 2019.

\section{APÊNDICE A}

\section{BLOCO 1 - EFEITOS EXTERNOS}

1. Que fatores externos (localização, acesso, mercado, etc.) afetam a competitividade de um porto?

2. Como um porto faz para mitigar os efeitos negativos dos fatores externos à gestão da AP e se tornar mais competitivo?

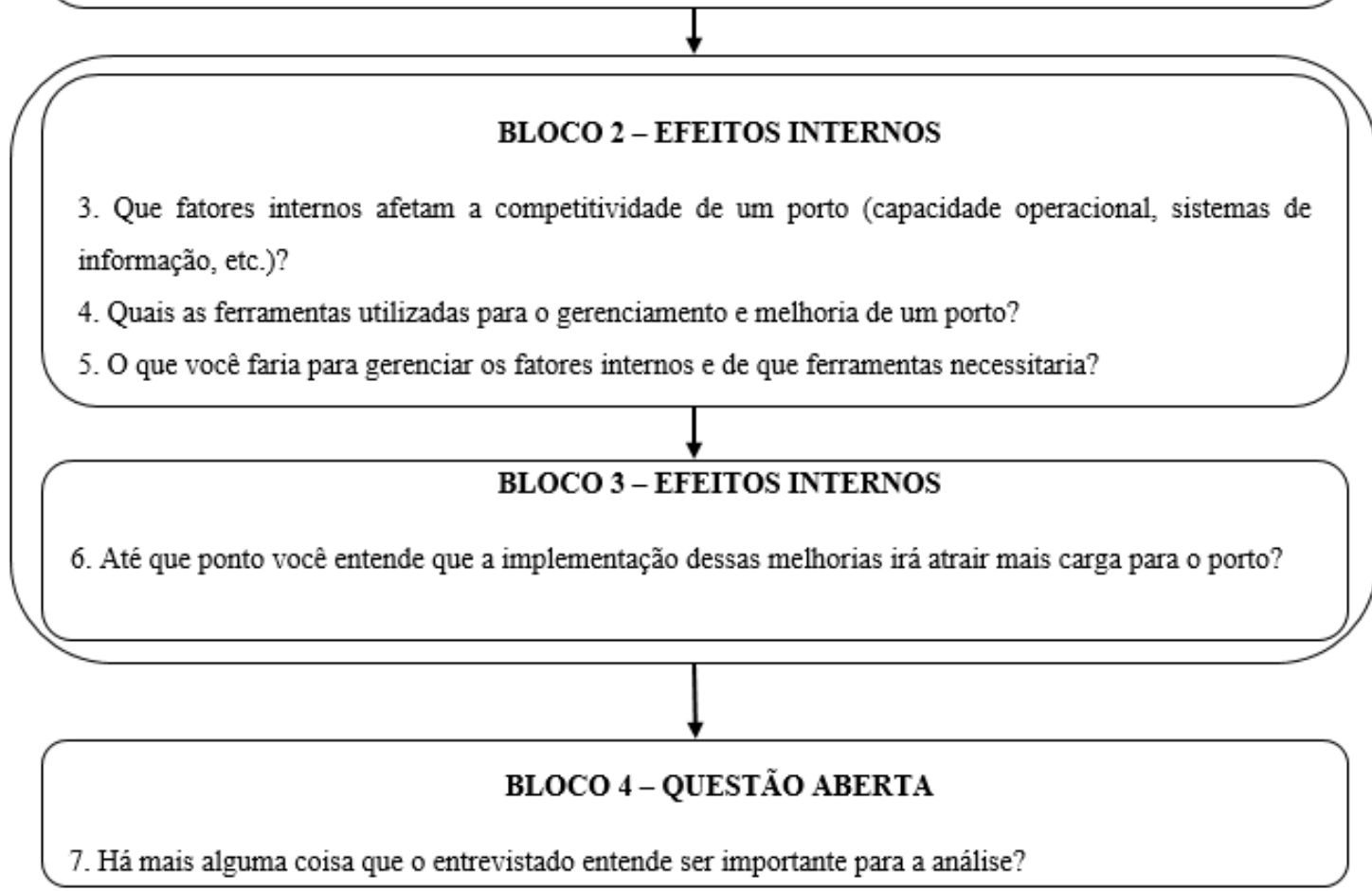

